\title{
Consolidation of Fe-Based Metallic Glass Powders by Hot Pressing
}

\author{
Diego de Araujo Santana ${ }^{a} \mathbb{D}^{\circ}$, Claudio Shyinti Kiminami ${ }^{b *}$ Francisco Gil Coury $^{a, c}$,
}

Giovanne Lopes Liberato ${ }^{b}$, Piter Gargarella ${ }^{b}$, Michael Joseph Kaufman

\author{
aPrograma de Pós-Graduação em Ciência e Engenharia de Materiais, Universidade Federal de São \\ Carlos, Rodovia Washington Luís, km 235, 13565-905, São Carlos, SP, Brasil \\ ${ }^{b}$ Departamento de Engenharia de Materiais, Universidade Federal de São Carlos, Rodovia Washington \\ Luís, $\mathrm{km}$ 235, 13565-905, São Carlos, SP, Brasil \\ ${ }^{c}$ Department of Metallurgical and Materials Engineering, Colorado School of Mines, 80401, Golden, \\ CO, USA
}

Received: August 21, 2018; Revised: November 10, 2018; Accepted: December 05, 2018

\begin{abstract}
An alternative route to obtain bulk metallic glasses is by consolidation of metallic glass powders by deforming these materials in the temperature interval between the crystallization temperature and the glass transition temperature, where the material flows with a reduced viscosity. In the present work, bulk parts of the $\mathrm{Fe}_{43.2} \mathrm{Co}_{28.8} \mathrm{~B}_{19.2} \mathrm{Si}_{4.8} \mathrm{Nb}_{4}$ alloy were produced by hot-pressing gas-atomized powders (GAP) under different uniaxial pressures. Different microstructural analysis revealed that the initial powder as well as the consolidated parts were mostly amorphous, with similar transformation temperatures, showing that bulk samples of this alloy can be produced by conformation in the supercooled liquid region. The sample conformed under the highest pressure (1GPa) exhibited the highest relative density of $96.1 \pm 0.5 \%$. These results show that hot pressing of Fe-based gas-atomized powders is a promising route for producing Fe-based bulk metallic glasses.
\end{abstract}

Keywords: Iron-based metallic glass alloys, atomization, hot pressing.

\section{Introduction}

Metallic glasses are a relatively new class of materials characterized by the absence of long-range ordering ${ }^{1,2}$. Due to their unique atomic structure, many unusual properties are observed in these alloys, such as high mechanical strength ${ }^{3}$, soft magnetic properties ${ }^{4}$ and good wear and corrosion resistance ${ }^{5}$, among others.

Iron-based metallic glasses often have complex compositions and usually exhibit poor glass forming ability (GFA) compared to other non-ferrous metallic glasses ${ }^{6}$. However, these alloys have attracted considerable attention due to their low cost, high availability, good soft magnetic properties and high mechanical strengths ${ }^{7,8}$. Among the iron-based alloys, the composition $\mathrm{Fe}_{43.2} \mathrm{Co}_{28.8} \mathrm{~B}_{19.2} \mathrm{Si}_{4.8} \mathrm{Nb}_{4}$ shows a relatively high GFA, being able to produce amorphous samples of up to $4 \mathrm{~mm}$ by copper mold casting ${ }^{9}$. Furthermore, it has a compressive yield strength above $4000 \mathrm{MPa}$, making it a promising candidate for applications in micro-engineering components.

Metallic glasses show a Newtonian flow when they are deformed at low strain rates within the supercooled liquid region, i.e., between the crystallization temperature, Tx, and the glass transition temperature, $\mathrm{Tg}{ }^{10-13}$. They exhibit a significant decrease in their viscosity in this temperature interval during heating and they are able to get wet and consequently adhere another metallic surface during this

*e-mail:kiminami@ufscar.br configurational rearrangement process. Some works have already used these properties to braze ${ }^{14}$, weld ${ }^{15}$ and consolidate metallic glasses ${ }^{16}$.

Only a very few works used these supercooled liquid properties to consolidate Fe-based metallic glasses ${ }^{17-19}$.

In this work, bulk parts of the $\mathrm{Fe}_{43.2} \mathrm{Co}_{28.8} \mathrm{~B}_{19.2} \mathrm{Si}_{4.8} \mathrm{Nb}_{4}$ alloy were produced by hot-pressing gas-atomized powders (GAP) at a temperature within their supercooled liquid interval.

\section{Experimental Procedure}

$\mathrm{An} \mathrm{Fe}_{43.2} \mathrm{Co}_{28.8} \mathrm{~B}_{19.2} \mathrm{Si}_{4.8} \mathrm{Nb}_{4}$ ingot was prepared by vacuum induction melting under an inert argon atmosphere using high purity elements, namely, iron (99.98 wt.\%), cobalt (99.9+ wt.\%), boron (99,5 wt.\%), silicon (99,9995 wt.\%) and niobium (99.8 wt.\%). The ingot chemical analysis was performed by inductively coupled plasma optical emission spectrometry (ICP-OES), using a spectrometer Varian model Vista. The ingot was remelted in an induction furnace and the molten alloy was poured into a tundish with a quartz nozzle with a bore of $4 \mathrm{~mm}$ diameter and atomized using nitrogen $\left(\mathrm{N}_{2}\right)$ with a 1.0 MPa pressure. The microstructure of the GAP was investigated by Optical Microscopy (OM) after chemical etching $\left(1,5 \mathrm{~g}\right.$ de picric acid $+100 \mathrm{~mL} \mathrm{H}_{2} \mathrm{O}$ $+20 \mathrm{~mL}$ neutral detergent) at $70^{\circ} \mathrm{C}$ and their morphology were characterized by scanning electron microscopy (SEM) using a FEI Inspect S 50 operating under $25 \mathrm{kV}$. The powders with particle size in the $32-75 \mu \mathrm{m}$ range were encapsulated 
in copper cans with an outer diameter of $14 \mathrm{~mm}$ and inner diameter of $12.7 \mathrm{~mm}$. Subsequently, they were consolidated by uniaxial hot pressing at $565^{\circ} \mathrm{C}$ during 300 s and at 325,700 and $1000 \mathrm{MPa}$, using an EMIC model DL-60.000 machine. These samples were named $\mathrm{C} 1, \mathrm{C} 2$ and $\mathrm{C} 3$, respectively. The microstructures of the hot pressed samples were also characterized by SEM. The amorphous state of the powders and consolidated samples were verified by X-Ray Diffraction in a Bruker D8 ADVANCE diffractometer operating with $\mathrm{Cu}$ $\mathrm{K} \alpha$ radiation. The $\mathrm{Tg}$ and $\mathrm{Tx}$ temperatures were determined by differential scanning calorimetry (DSC) using a Netzsch 404 instrument at a heating rate of $40{ }^{\circ} \mathrm{C} / \mathrm{min}$. The density of the powders was determined using a helium pycnometer Micromeritics AccuPyc 1330 equipment and density of the consolidated samples was measured by Archimedes' method.

\section{Results and Discussion}

The results of the ingot chemical analysis show that a very close composition to the target one was achieved, namely $\mathrm{Fe}_{42.4} \mathrm{Co}_{30.3} \mathrm{~B}_{18.0} \mathrm{Si}_{5.2} \mathrm{Nb}_{4.0}$ (nominal composition = $\left.\mathrm{Fe}_{43.2} \mathrm{Co}_{28.8} \mathrm{~B}_{19.2} \mathrm{Si}_{4.8} \mathrm{Nb}_{4.0}\right)$.

The gas-atomized powders with particle size in the range 32-75 $\mu \mathrm{m}$ can be seen in Figure 1 (a). Most of particles had a spherical shape and a clean surface, typical of amorphous powders ${ }^{20}$. Some irregularly shaped particles can be also observed in Figure 1 (a). These particles most likely hit the atomization chamber without being completely solidified, and were deformed by the impact. Crystalline regions were detected by optical microscopy after chemical etching, as indicated by red arrows in Figure 1 (b).

The yield strength of $\mathrm{Fe}_{43.2} \mathrm{Co}_{28.8} \mathrm{~B}_{19.2} \mathrm{Si}_{4.8} \mathrm{Nb}_{4}$ alloy is reported to be $4100 \mathrm{MPa}$ at room temperature ${ }^{9}$. Assuming that alloy shows a Newtonian flow within its supercooled interval and its viscosity $(\eta)$ is in the range $10^{8}-10^{9}$ Pa.s, similar to $\mathrm{Fe}_{36.0} \mathrm{Co}_{36.0} \mathrm{~B}_{19.2} \mathrm{Si}_{4.8} \mathrm{Nb}_{4}$ glassy alloy ${ }^{21}$, the flow stress in the supercooled liquid region under a uniaxial compression test and constant temperature can be estimated by equation $1^{22}$ :

$$
\sigma=3 \eta \dot{\varepsilon}
$$

where $\dot{\varepsilon}$ is the uniaxial strain rate. Considering a typical value of $0.1 \mathrm{~s}^{-1}$ for $\dot{\varepsilon}$, the uniaxial flow stress within the supercooled interval would be in the 30-300 MPa range. This low value suggests that consolidation of glassy powders in the supercooled liquid region is a promising route to produce bulk parts of $\mathrm{Fe}_{43.2} \mathrm{Co}_{28.8} \mathrm{~B}_{19.2} \mathrm{Si}_{4.8} \mathrm{Nb}_{4}$ alloy.

Figure 2 shows the DSC curves of the GAP and the hot-pressed samples. The transformation temperatures $\mathrm{Tg}$, $\mathrm{Tx}$ and $\Delta \mathrm{Tx}(=\mathrm{Tx}-\mathrm{Tg})$, are summarized in Table 1 together with the data reported by Inoue et al. ${ }^{9}$. The powders glass transition temperature is $550 \pm 2^{\circ} \mathrm{C}$. After a supercooled liquid of about $40 \pm 3{ }^{\circ} \mathrm{C}$, an exothermic event can be observed, characteristic of crystallization. $\mathrm{Tg}$ is similar to the reported data in the literature, but Tx is about $8^{\circ} \mathrm{C}$ lower. Although the GAP and casted cylinders of the literature were probably formed under different cooling rates, $\mathrm{Tg}$ is often determined experimentally during heating. When heated, the glassy alloy is structurally relaxed and therefore $\mathrm{Tg}$ is expected to be similar when the same heating rate is applied. The decrease of Tx reinforce that the GAP presents some degree of crystallinity, as crystalline phases serve as nucleation points, reducing $\Delta \mathrm{Tx}$.

All the consolidation experiments were carried out at $565{ }^{\circ} \mathrm{C}$ (which corresponds to Tg plus $15^{\circ} \mathrm{C}$ ). $\mathrm{C} 1$, the sample consolidated with the smallest pressure, i.e. $325 \mathrm{MPa}$, disintegrated upon cutting. Figure 3 shows a micrograph of the $\mathrm{C} 1$ sample that remained bonded. As it can be noticed, the reason for the weak bonding among the powders can
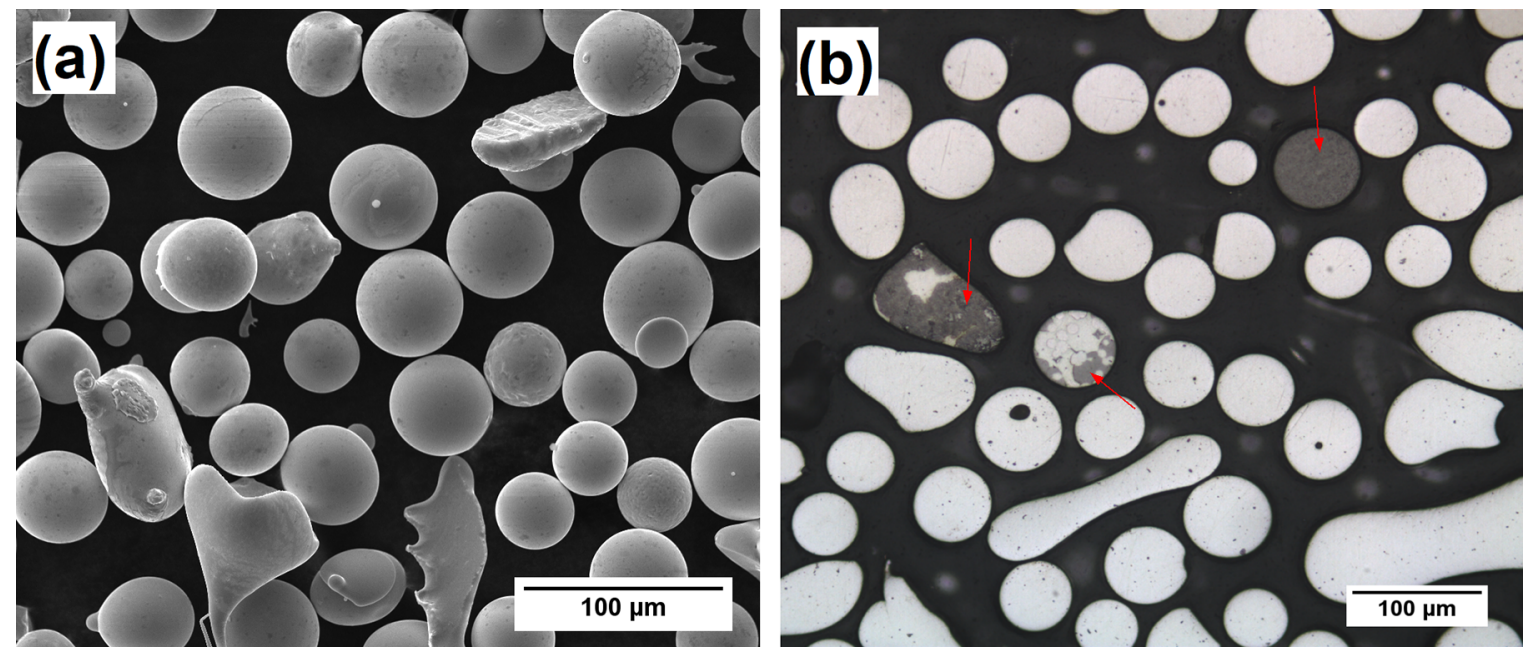

Figure 1. Micrographs of the $\mathrm{Fe}_{43.2} \mathrm{Co}_{28.8} \mathrm{~B}_{19.2} \mathrm{Si}_{4.8} \mathrm{Nb}_{4}$ gas atomized powders in the $32-75 \mu \mathrm{m}$ range. (a) SEM - Secondary Electron (SE) image showing the morphology of the particles. (b) Mounted and etched OM micrograph showing that some particles are crystalline. The red arrows indicate the crystalline regions. 
be explained by their low deformation, resulting in a low contact area between the particles.

By almost doubling the applied pressure in the $\mathrm{C} 2$ sample, the particles were highly deformed, which enabled the sample to be cut, gridded and polished. Figure 4 (a) shows the cross section of $\mathrm{C} 2$. The increase in pressure lead to a better bonding between the particles, i.e. a much larger contact area can be observed between the powder particles. However, it is clear that the powders were still not completely packed. The density of the atomized powders measured by helium pycnometer was $7.64 \pm 0.02 \mathrm{~g} / \mathrm{cm}^{3}$. This value was used to calculate the relative density (RD) of the samples. A RD of $90.6 \pm 0.5 \%$ was obtained for $\mathrm{C} 2$.

The highest compression load used in this work was $1 \mathrm{GPa}$, for the $\mathrm{C} 3$ sample, in which a relative density of $96.1 \pm 0.5 \%$ was obtained. In contrast to $C 2$, only small pores still remain on the microstructure of $\mathrm{C} 3$, as can be seen in Figure 4 (b).

Differently from what was initially expected, a high pressure is necessary to produce consolidated glassy parts with a high RD. Considering that glassy powders do not show work hardening behavior ${ }^{12}$, the high pressure is most likely due to one of the following factors: friction effects between the particles, some degree of crystallinity in the powders and/or low pressing temperature, which leads to a higher flow stress, since the viscosity decreases with temperature up to $\mathrm{Tx}^{21}$.

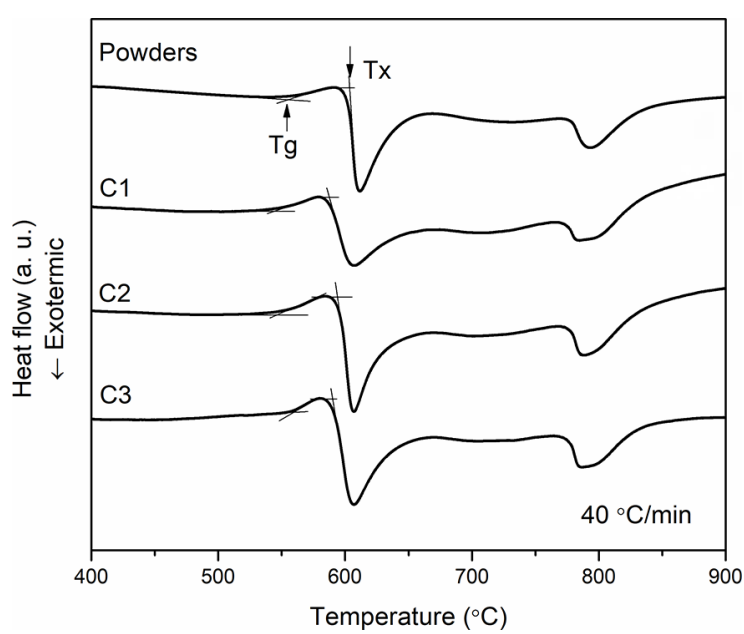

Figure 2. DSC curves of the GAP and the consolidated samples.
It has been reported that an oxide layer present in the powder surface can avoid a strong bonding between the glassy powders particles when no pressure is applied ${ }^{23,24}$. High pressures will break the oxide layer, however, they are usually limited by the used tools. As seen in this work, this necessary pressure to consolidate amorphous parts are much higher than the theoretical stress to flow fully amorphous powder particles. This poses a processing issue since to consolidate bigger parts, very high loads are necessary.

No appreciable difference in the transformation temperatures $\mathrm{Tg}$, $\mathrm{Tx}$ and thus $\Delta \mathrm{Tx}$ is noticed between the as-atomized powders and hot-pressed samples. This reveals that the consolidation processes were successfully carried out within the supercooled liquid interval avoiding further crystallization. Furthermore, the exothermic peak in the DSC curve proves the presence of an amorphous phase in the consolidated samples, since only a crystallization event could explain the exothermic event at that temperature range in the $\mathrm{Fe}_{43.2} \mathrm{Co}_{28.8} \mathrm{~B}_{19.2} \mathrm{Si}_{4.8} \mathrm{Nb}_{4}$ alloy.

Figure 5 shows XRD patterns of the powders and hotpressed samples. A halo around $2 \theta=44^{\circ}$, typical of an amorphous structure, can be seen in the XRD patterns. The presence of some wide Bragg peaks in the patterns can also be noted, corroborating with the OM images and DSC results.

Overall, it was shown that bulk glassy samples of the $\mathrm{Fe}_{43.2} \mathrm{Co}_{28.8} \mathrm{~B}_{19.2} \mathrm{Si}_{4.8} \mathrm{Nb}_{4}$ alloy can be produced by hot pressing gas atomized powders in the supercooled liquid region. The

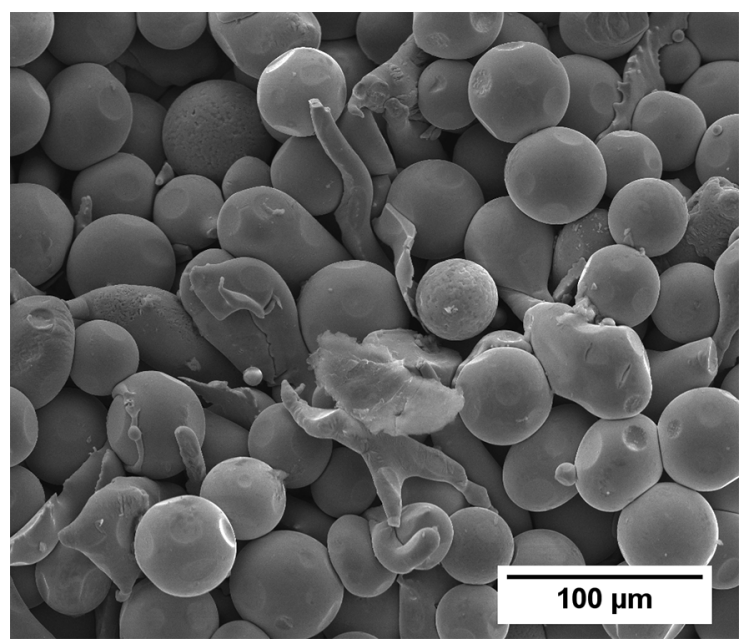

Figure 3. SEM-SE micrograph showing the surface of the $\mathrm{C} 1$ sample.

Table 1. The transformation temperatures $\mathrm{Tg}$, $\mathrm{Tx}$ and $\Delta \mathrm{Tx}(=\mathrm{Tx}-\mathrm{Tg})$, measured density and mean hardness value of the GAP and consolidated samples.

\begin{tabular}{lccccc}
\hline $\mathrm{Fe}_{43,2} \mathrm{Co}_{28,8} \mathrm{~B}_{19,2} \mathrm{Si}_{4,8} \mathrm{Nb}_{4}$ & $\begin{array}{c}\text { Applied pressure } \\
(\mathrm{MPa})\end{array}$ & $\mathrm{Tg}\left({ }^{\circ} \mathrm{C}\right)$ & $\mathrm{Tx}\left({ }^{\circ} \mathrm{C}\right)$ & $\Delta \mathrm{Tx}\left({ }^{\circ} \mathrm{C}\right)$ & $\begin{array}{c}\text { Relative Density } \\
(\%)\end{array}$ \\
\hline Literature & - & 552 & 602 & 50 & - \\
$\mathrm{GAP}$ & - & $550 \pm 2$ & $590 \pm 2$ & $42 \pm 3$ & - \\
$\mathrm{C} 1$ & $325 \pm 1$ & $544 \pm 2$ & $589 \pm 2$ & $45 \pm 3$ & - \\
$\mathrm{C} 2$ & $700 \pm 1$ & $553 \pm 2$ & $593 \pm 2$ & $40 \pm 3$ & $90.6 \pm 0.5$ \\
$\mathrm{C} 3$ & $1000 \pm 1$ & $556 \pm 2$ & $591 \pm 2$ & $35 \pm 3$ & $96.1 \pm 0.5$ \\
\hline
\end{tabular}



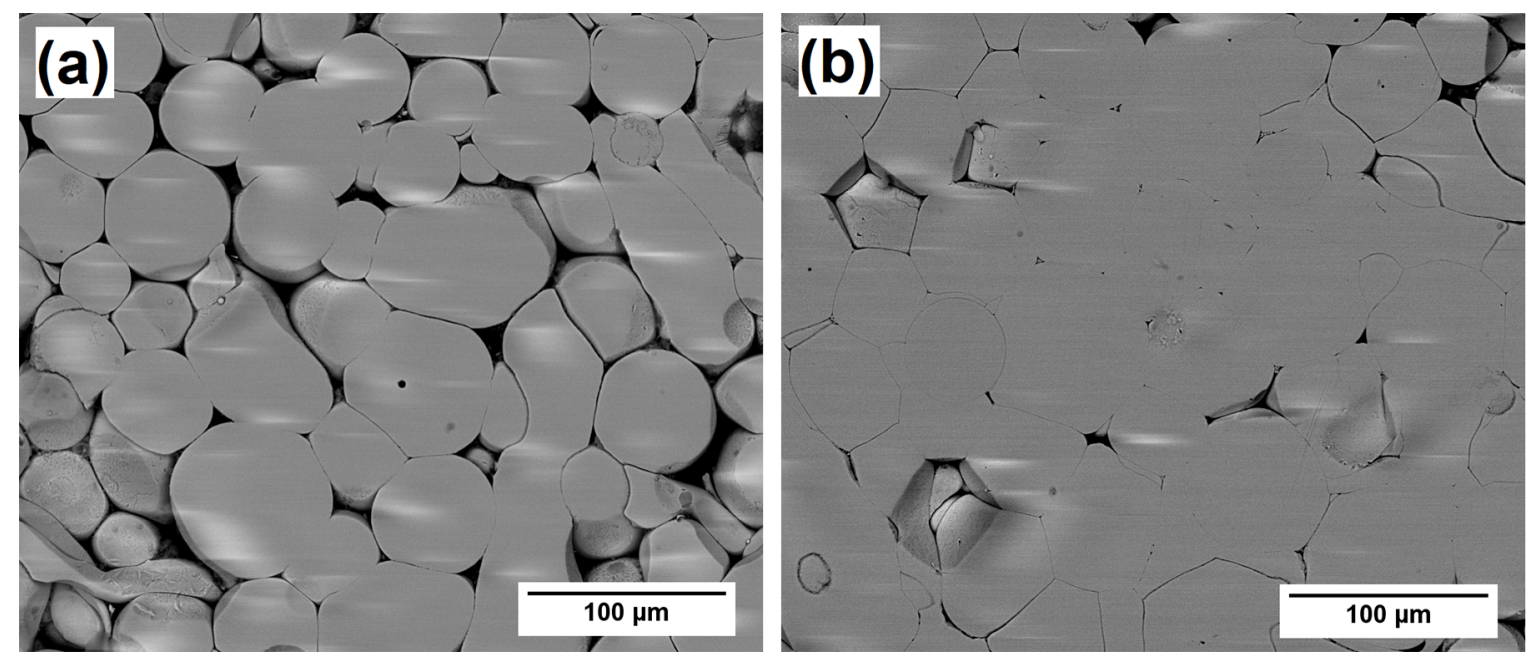

Figure 4. SEM - Backscattered Electron (BSE) micrographs of the cross section of the consolidated samples (a) C2 and (b) C3.

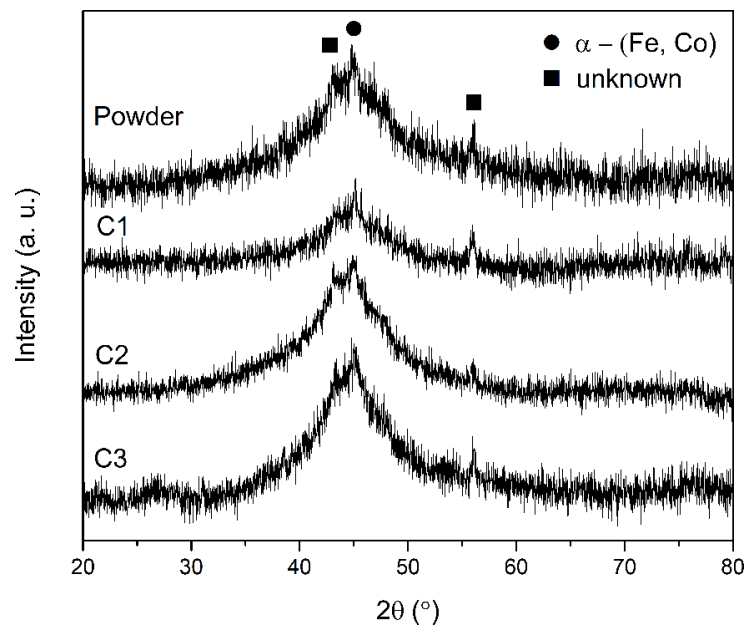

Figure 5. XRD patterns of the GAP and the consolidated samples.

obtained relative density was relatively high but the pressure necessary for consolidating these samples was much higher than expected, considering typical viscosity values of these materials. In the future, a better understating of the flow of atomized powders in the supercooled liquid region should be pursed in order to optimize the conformation process of these alloys.

\section{Summary and Conclusions}

Bulk amorphous parts of the $\mathrm{Fe}_{43,2} \mathrm{Co}_{28,8} \mathrm{~B}_{19,2} \mathrm{Si}_{4,8} \mathrm{Nb}_{4}$ alloy were produced via consolidation of gas-atomized powders. Gas atomized powders below $75 \mu \mathrm{m}$ were mostly spherical and had a clean surface. Although the consolidation process was carried out within the powders supercooled liquid interval, a high pressure (1GPa) was necessary to produce parts with high relative density $(96.1 \%)$. The compacts present glass transition and crystallization temperatures as well diffraction patterns similar to the atomized powders indicating that the same amorphous structure from the powders was present in the bulk samples. The proposed consolidation method is a promising route for producing bulk metallic glasses.

\section{Acknowledgements}

The authors thank the grant \#2015/26705-6, São Paulo Research Foundation (FAPESP) and National Council for Scientific and Technological Development (CNPq - Brazil) for financial support.

\section{References}

1. Greer AL. Metallic glasses...on the threshold. Materials Today. 2009;12(1-2):14-22.

2. Suryanarayana C, Inoue A. Bulk Metallic Glass. 1st ed. Boca Raton: CRC Press; 2010. 565 p.

3. Ashby MF, Greer AL. Metallic glasses as structural materials. Scripta Materialia. 2006;54(3):321-326.

4. Hasegawa R. Applications of amorphous magnetic alloys in electronic devices. Journal of Non-Crystalline Solids. 2001;287(1-3):405-412.

5. Ishida M, Takeda H, Nishiyama N, Kita K, Shimizu Y, Saotome $\mathrm{Y}$, et al. Wear resistivity of super-precision microgear made of Ni-based metallic glass. Materials Science and Engineering: A. 2007;448-451:149-154.

6. Suryanarayana C, Inoue A. Iron-based bulk metallic glasses. International Materials Reviews. 2013;58(3):131-166.

7. Inoue A, Kong FL, Man QK, Shen BL, Li RW, Al-Marzouki F. Development and applications of Fe- and Co-based bulk glassy alloys and their prospects. Journal of Alloys and Compounds. 2015;615(Supp 1):S2-S8.

8. Stoica M. Fe-Based Bulk Metallic Glasses - Understanding the Influence of Impurities on Glass Formation. Wiesbaden: Springer Fachmedien Wiesbaden; 2017. 126 p. 
9. Inoue A, Shen BL, Chang CT. Super-high strength of over $4000 \mathrm{MPa}$ for Fe-based bulk glassy alloys in [(Fe1xCox) $0.75 \mathrm{~B} 0.2 \mathrm{Si} 0.05] 96 \mathrm{Nb} 4$ system. Acta Materialia. 2004;52(14):4093-4099.

10. Kawamura Y, Nakamura T, Kato H, Mano H, Inoue A. Newtonian and non-Newtonian viscosity of supercooled liquid in metallic glasses. Materials Science and Engineering: $A$. 2001;304-306:674-678.

11. Yavari AR, de Oliveira MF, Kiminami CS, Inoue A, Botta Filho WJ. Electromechanical shaping, assembly and engraving of bulk metallic glasses. Materials Science and Engineering: A. 2004;375-377:227-234.

12. Schuh CA, Hufnagel TC, Ramamurty U. Mechanical behavior of amorphous alloys. Acta Materialia. 2007;55(12):4067-4109.

13. Kawamura Y, Shibata T, Inoue A, Masumoto T. Deformation behavior of Zr65A110Ni10Cu15 glassy alloy with wide supercooled liquid region. Applied Physics Letters. 1996;69(9):1208-1210.

14. Suh JY, Lohwongwatana B, Garland CM, Conner RD, Johnson WL, Suh D. Novel thermoplastic bonding using a bulk metallic glass solder. Scripta Materialia. 2008;59(8):905-908.

15. de Oliveira M, Botta Filho WJ, Yavari AR. Connecting, Assemblage and Electromechanical Shaping of Bulk Metallic Glasses. Materials Transactions, JIM. 2000;41(11):1501-1504.

16. Sordelet DJ, Rozhkova E, Huang P, Wheelock PB, Besser MF, Kramer MJ, et al. Synthesis of Cu47Ti34Zr11Ni8 Bulk Metallic Glass by Warm Extrusion of Gas Atomized Powders. Journal of Materials Research. 2002;17(1):186-198.
17. Ishihara S, Zhang W, Inoue A. Hot pressing of Fe-Co-Nd-Dy-B glassy powders in supercooled liquid state and hard magnetic properties of the consolidated alloys. Scripta Materialia. 2002;47(4):231-235.

18. Kang EY, Kim YB, Kim KY, Chung YH, Baik HK. Vacuum hot pressing of Fe-Si-B-Nb-based amorphous powder cores and their high-frequency magnetic properties. Journal of Applied Physics. 2006;99(8):08F111.

19. Yodoshi N, Yamada R, Kawasaki A, Watanabe R. Consolidation of [(Fe0.5Co0.5)0.75 $\mathrm{Si} 0.05 \mathrm{~B} 0.2] 96 \mathrm{Nb} 4$ Metallic Glassy Powder by SPS Method. Materials Transactions. 2009;50(9):2264-2269.

20. German RM. Powder Metallurgy \& Particulate Materials Processing. Princeton: Metal Powder Industry Federation; 2005. $528 \mathrm{p}$.

21. Parthiban R, Stoica M, Kaban I, Kumar R, Eckert J. Viscosity and fragility of the supercooled liquids and melts from the $\mathrm{Fe}$ $\mathrm{Co}-\mathrm{B}-\mathrm{Si}-\mathrm{Nb}$ and $\mathrm{Fe}-\mathrm{Mo}-\mathrm{P}-\mathrm{C}-\mathrm{B}-\mathrm{Si}$ glass-forming alloy systems. Intermetallics. 2015;66:48-55.

22. Trouton FT. On the Coefficient of Viscous Traction and Its Relation to that of Viscosity. Proceedings of the Royal Society of London. Series A: Mathematical, Physical and Engineering Sciences. 1906;77(519):426-440.

23. Yan M, Yu P, Kim KB, Lee JK, Schaffer GB, Qian M. The surface structure of gas-atomized metallic glass powders. Scripta Materialia. 2010;62(5):266-269.

24. Kawamura Y, Inoue A, Masumoto T. Mechanical properties of amorphous alloy compacts prepared by a closed processing system. Scripta Metallurgica et Materialia. 1993;29(1):25-30. 